\title{
Chakras' Energies Deficiencies as the Main Cause of Myocardial Infarction without Arterial Obstruction
}

\author{
Huang WL* \\ Infectious Diseases, Medical Acupuncture and Pain Management Clinic, Brazil
}

*Corresponding author: Huang Wei Ling, Infectious Diseases, Medical Acupuncture and Pain Management Clinic, São Paulo, Brazil.

Received Date: December 09, 2020

Published Date: January 18, 2021

\begin{abstract}
Introduction: Myocardial infarction with nonobstructive coronary arteries (MINOCA) is the term currently used to describe patients presenting with clinical features of an acute myocardial infarct (MI) but without evidence of obstructive coronary artery disease (CAD) on coronary angiography. The causes in Western medicine are divided in coronary causes and non coronary causes.

Purpose: Is to demonstrate another possible cause of non coronary myocardial infaction that is related to energies deficiencies in the Chakras' energies centers, not visible by the naked eyes.

Method: A case report of a 60 year-old-women, with a history of pain in the chest and irradiation to the left upper limb in december 2019. She went to a hospital and was submitted an exams that demonstrated alterations in cardiac enzimes. The doctors decided to submite her to a coronary angiography that resulted in normal exam. After two months, she had another episode of chest pain and was submitted to the same coronary angiography and they decided to put a stent. Another new episode of chest pain in march 2020, after she was kidnapped, and submited again to a new anterial coronary angiography because of alterations in cardiac enzimes. The exams resulted in normal again, without any obstruction. She began to do acupuncture to recover from the stress after the kidnap and the traditional Chinese medicine doctor decided to evaluate her chakras' energies centers with intention to see the possibility of low energy in the chakras' that could lead her to more propensity to SARS-CoV-2 infection.

Results: All her chakras' were completely depleted in energy and the doctor began to treat these energies deficiencies with homeopathies according to the theory created by her Constitutional Homeopathy of Five Elements Based on Traditional Chinese Medicine and crystal based medications. In the beginning of the treatment, the patient did not say to the doctor that she had myocardial infartion but the doctor noticed that all the points where the acupuncture neddle was inserted was being purple and the patient told the doctor that it was because she was using aspirine from the treatment of myocardial infartion she had few months ago.
\end{abstract}

Conclusion: the conclusion of this study is that, the possible factor that had induce the myocardial infarction in this patient was the complete lack of energy in all her chakras' energies centers, leading to stagnation of Blood in the coronary arteries. The correct treatment of this lack of energy will prevent future myocardial infartions events and prevent the development of another diseases.

Keywords: Myocardial infarction; Energy; Chakras; Traditional Chinese Medicine; Diet; Homeopathy; Hippocrates

\section{Introduction}

Myocardial infarction with non-obstructive coronary arteries (MINOCA) is the term currently used to describe patients presenting with clinical features of an acute myocardial infarct (AMI) but without evidence of obstructive coronary artery disease (CAD) on coronary angiography [1]. MINOCA is found in roughly $6 \%$ of

AMI patients; however, there is large variability in its reported prevalence, with a range of $3.5 \%$ to $15 \%$, possibly attributable to differences in the studied populations and heterogeneity in its definition. It is also more common in younger patients and women [2]. 


\section{Purpose}

The purpose of this article is to demonstrate another possible cause of non coronary myocardial infaction that is related to energies deficiencies in the chakras' energies centers, not visible by the naked eyes.

\section{Methods}

To write this article, the author compile literature from Western medicine and traditional Chinese medicine publications indexed in PubMed related to myocardial infarction without obstruction and also, she used one case report to illustrate this article. The patient reported in the case report suffered from three episodes of myocardial infarction and the doctors did not found obstruction in two of the three episodes of myocardial infarction.

\section{Case Report}

It is a 60-year-old woman, that began to do acupuncture, from her husband recommendation that was already the author's patient, after she being kidnapped, as she was very scared and stressed. The physician decided to evaluate her chakras' energies meridians once her husband had already measured his energy and was in the minimum level and as all the world were in the middle of an infectious disease pandemic, it was important to improve her energies levels because, energy means immune system and if the patient has low energy levels, she could be more prone to acquire some disease, in this specific case, we were focusing on the chance of acquiring the SARS-CoV-2 infection. All her chakras' were completely depleted in energy, rated in one out of eight with the exception of the seventh, that was rated in eight (normal) and the author began to treat these energies deficiencies with homeopathy according to the theory created by her entitled Constitutional Homeopathy of Five Elements Based on Traditional Chinese Medicine and crystal based medications.

During the acupuncture sessions, the author noticed that all the points where the acupuncture needle was inserted was being purple and the patient told to the author that it was because she was using aspirin from the treatment of myocardial infarction that she had six months ago (the first myocardial infarction was in December 2019, the second was in the beginning of 2020 and the third one was in march 2020). So she told to the author that in December 2019 felt pain in the chest and irradiation to the left upper limb, she went to a hospital and was submitted to some exams that demonstrated alterations in cardiac enzymes. The doctors decided to submit her to a coronary angiography that resulted in normal exam. After two months, she had another episode of chest pain and was submitted to the same coronary angiography and they decided to put a stent. Another new episode of chest pain in march 2020, after she was kidnapped, and submitted again to a new arterial coronary angiography because of alterations in cardiac enzymes. The exams resulted in normal again, without any obstruction. Only in the second infarction, an obstruction of $70 \%$ was supposedly found, but it does not make sense that an artery was obstructed in two months and one month after the stand placement was unobstructed, said by the patient.

The Chinese dietary counseling was the first recommendation made by author for this patients and for to replenish the energy of each massive organ, some foods must be avoided. To do notimbalance the Spleen-pancreas meridian, the patient was orientated to avoid raw food, cold water, sweets and dairy products. In order not to further imbalance the Kidney meridian, it was recommended that the patient drink plenty of water, not cold water, but at a neutral or warm temperature, in addition to avoiding the intake of soda, coffee and matte tea. To help the Lung meridian it is recommended that the patient eat broccoli and cauliflower. In order to diminish the internal Heat formation and the imbalance of the Liver meridian the patient has to be oriented to avoid the consumption of melted cheese, chocolate, honey, eggs, alcoholic beverages and coconut. The homeopathic medications were prescribed according to the following sequence: Sulphur 30CHXX-20 (single dose), Calcarea carbonica 30CHXX-20 (single dose), Silicea 30CHXX-20 (single dose), Natrium muriaticum 30CHXX-20 (single dose), Phosphorus 30CHXX-20. The homeopathies were prescribed to be taken in a single dose with a hiatus of three days between the medications, necessarily on the sequence described. Two months later, a new sequence of treatment was started, with the same medications taken on the same order, but now with 200CHXX-20 instead of 30 CHXX-20. Two months later, a new sequence of treatment was started, as the others, with the same medications taken on the same order, now with 1000CHXX-20 instead of 200CHXX-20. Two months later, a new sequence of treatment was started, as the others, with the same medications taken on the same order, now with 10000CHXX-20 instead of 1000CHXX-20. Two months later, a new sequence of treatment was started, as the others, with the same medications taken on the same order, now with 50000CHXX20 instead of 0000CHXX-20.

The crystal based medications will be described in the discussion session, and were instructed to intake them for the period of one year or more, when new chakras' energies centers measurement need to be done again.

\section{Results of the Case Report}

After she began to treat her chakras' energies centers, that was completely deficient in energy, she did not have any more myocardial infarction. During these period until the author compile her case to publish she had COVID -19, but the symptoms were mild, only having some runny nose and pain the body, not need to be admitted in the hospital because of this infection.

\section{Discussion}

To write this article and the reasoning the author used to do the diagnosis and treatment was based on Hippocrates quotes that said that it is important to consider other ancient medical 
traditions prior to the knowledge we have nowadays and for this reason the author chooses to develop this article using traditional Chinese medicine reasoning, together with what we have nowadays regarding myocardial infarction without arterial obstruction [34]. Myocardial infaction, when no obstructive coronary arteries are found, is considered a syndrome with differents causes. The prevalence of this kind of myocardial infaction ranges from 5 to 25 percent when compared to all myocardial infaction. The normal exams usually done is necessary such as echocardiography, coronary angiography and left ventriculography, but other additional testes normally are require to establish the specific cause, and allowing appropriate risk stratification and treatment [5]. Before the author explains the basis of traditional Chinese medicine reasoning to explain the physiopathology of how the energies deficiencies could lead to myocardial infarction without arterial obstruction, she would like show the reasoning she used in all her treatments nowadays that started during the treatment of one specific patient in 2006 [6].

This patient was a 70-year-old patient, who reported pain in the legs and was diagnosed with Kidney-Yang deficiency, according to traditional Chinese medicine (TCM). He was using antiinflammatory medications for six months with no improvement. $\mathrm{He}$ received treatment with Chinese dietary counseling, acupuncture and auricular acupuncture associated with apex ear bloodletting [6]. With the treatment done, the pain in the legs diminished and the patient was submitted to an interview 30 days after the treatment. In this interview, the patient revealed that his eye pressure had also lowered, as his ophthalmologist confirmed. During the treatment, he had not reported to be treating glaucoma in the last 40 years with no improvement of his condition [6]. This unusual case became the cornerstone of the author's studies in the field, trying to comprehend how the treatment focused on the root of the problem could treat different diseases and symptoms simultaneously and using the same methods [6]. To explain the different perspectives between Western medicine and traditional Chinese medicine, the author will use the metaphor of the tree, published in many other articles written by the author, in the most varied diseases and specialties (Figure 1) [7-14].

In this metaphor the patients' symptoms are considered the leaves of the tree and the specialties of Western medicine are the branches. However, traditional Chinese medicine looks at the entire tree, focusing on its root, which is represented by the theories of Yin and Yang and the Five Elements that are responsible for the energy of the patients, so, when treating the energy level, all the tree will be healthy again. These energies can also be influenced by the external pathogenic factors described in TCM: Wind, Cold, Heat, Dryness and Humidity (Figure 2) [7-14]. The Yin and Yang are the theory basing traditional Chinese medicine. According to Chinese wise men, everything in the world is ruled by the measure of balance between Yin and Yang. Everything is cyclical, and there are always principals of opposites completing themselves in everything in the universe. Yin and Yang symbol shows the symmetrical arrangement of the dark Yin and the light Yang; the symmetry, however, is not static [7-15]. For Yin and Yang energy to flow, two other energies have to work in harmony with it: Qi and Blood. To achieve health, the main aim is to balance these four energies Yin, Yang, Qi and Blood, as demonstrated in the (Figure 3). This theme was presented at the Acupuncture Research Conference, in 2015, at Harvard Medical School, in Boston and the title of this presentation was Acupuncture Viewed Holistically Can Treat all Patient Disease at the Same Time, even the doctor doesn't know that the patient has such symptoms [7-15]. The lack of energy of one of these energies or a combination of them can lead to the formation of internal Heat inside the body, as you can see in the (Figure 4) [7-15]. To diagnose the energy imbalances of the patient (Yin, Yang, Qi, Blood and Heat retention) a series of questions are used in the first appointment of the patient and are described in the (Table 1).

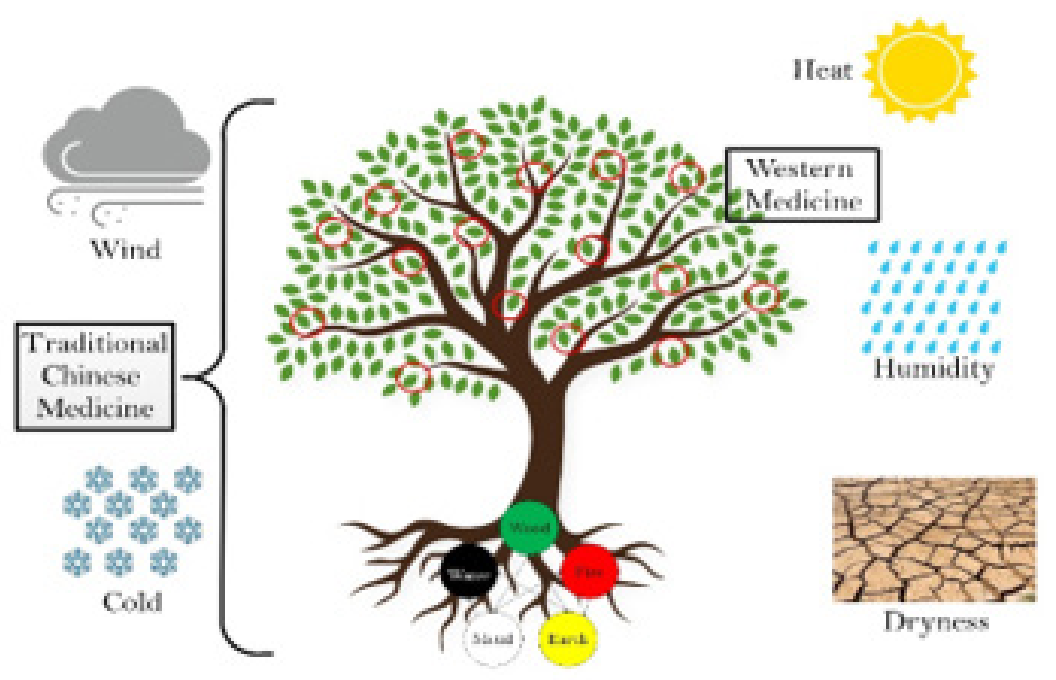

Figure 1: Metaphor of the tree. 


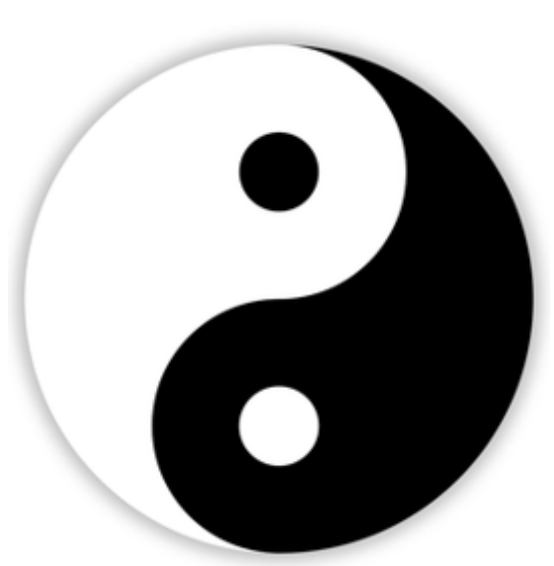

Figure 2: Yin and Yang.

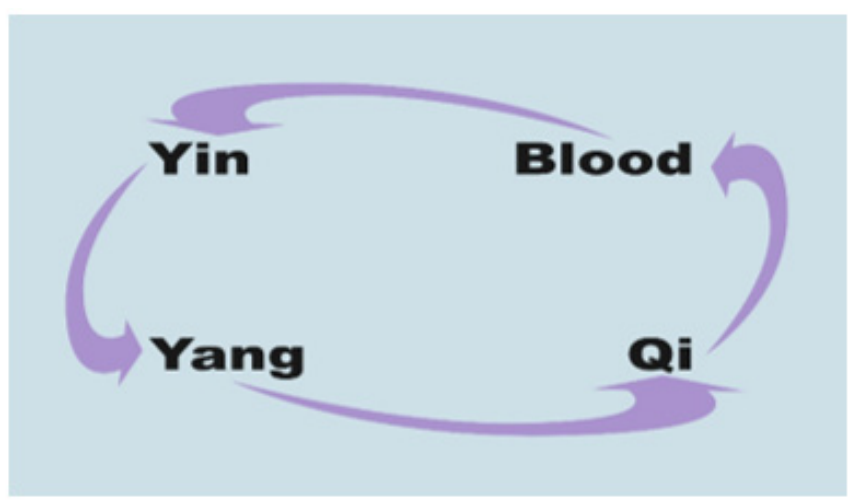

Figure 3: Yin, Yang, Qi and Blood.

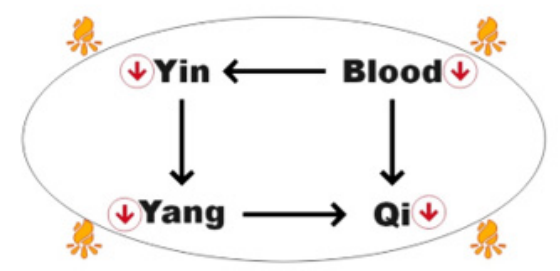

Figure 4: Yin, Yang, Qi, Blood Heat retention.

Table 1: How to Diagnose Yin, Yang, Qi, Blood and Heat retention.

\begin{tabular}{|c|c|c|c|c|c|}
\hline Question & $\begin{array}{c}\text { Does the patient } \\
\text { have a daily bowel } \\
\text { movement? }\end{array}$ & $\begin{array}{c}\text { Does the patient have } \\
\text { excessive sweating } \\
\text { during day? }\end{array}$ & $\begin{array}{c}\text { Does the patient } \\
\text { feel cold in the } \\
\text { extremities of the } \\
\text { body? (Cold feet or } \\
\text { hands) }\end{array}$ & $\begin{array}{c}\text { Does the patient } \\
\text { feel hot in the } \\
\text { extremities? }\end{array}$ & $\begin{array}{c}\text { Does the patient have dry } \\
\text { mouth, bleeding gums, } \\
\text { bad breath acne and/ } \\
\text { or redness in the skin, } \\
\text { abdominal pain, micro } \\
\text { hematuria, or itching? }\end{array}$ \\
\hline Meaning & $\begin{array}{c}\text { The lack of daily } \\
\text { bowel movements } \\
\text { can mean Blood } \\
\text { deficiency. }\end{array}$ & $\begin{array}{c}\text { This could be a } \\
\text { symptom of } Q i \\
\text { deficiency. }\end{array}$ & $\begin{array}{c}\text { Commonly, this } \\
\text { is a sign of Yang } \\
\text { deficiency. }\end{array}$ & $\begin{array}{c}\text { Commonly a sign of } \\
\text { Yin deficiency. }\end{array}$ & $\begin{array}{c}\text { Commonly this is a sign of } \\
\text { Heat retention. }\end{array}$ \\
\hline
\end{tabular}

* Blood deficiency can be understood as anemia in the energy level. As Blood deficiency may take years to appear in the laboratory exams, the patient with constipation and a normal complete blood count (CBC) can still be considered a patient with Blood deficiency, according to TCM.

If the patient does not have daily bowel movements, this may mean that the patient has Blood deficiency. If the patient has excessive sweating during the day, this may be a symptom of $Q i$ deficiency. If the patient feels colder on the extremities of the body, with cold feet or hands, this may be related to Yang deficiency. On the other hand, when the patient feels hotter on the extremities of the body, this may be a sign of Yin deficiency. If the patient has dry mouth, bleeding gums, bad breath, acne and/or redness in the skin, abdominal pain, micro hematuria or itching, this may be a sign of Heat retention [7-16]. At the root of the tree there are two theories: 
the first is the theory of the Five Elements (Wood, Fire, Earth, Metal and Water) that are in dynamic balance and each element is represented by a massive organ of the human body (Liver, Heart, Spleen, Lungs and Kidney respectively), and each massive organ

Table 2: Resonance of the Five Elements. has a hollow organ that they correspond (Figure 5), the external sensorial organ, among other specifications, demonstrated in the (Table 2) [7-16].

\begin{tabular}{|c|c|c|c|c|c|}
\hline & Wood & Fire & Earth & Metal & Water \\
\hline Orientation & East & South & Middle & West & North \\
\hline Season & Spring & Summer & Late Summer & Autumn & Winter \\
\hline Climate & Wind & Summer Heat & Dampness & Dryness & Rold \\
\hline Cultivation & Germinate & Grow & Transfrom & Reap & Kidney \\
\hline Yin Organ & Liver & Heart & Spleen & Lung & Bladder \\
\hline Yang Organ & Gall Bladder & Small Intestine & Stomach & Large Intestine & Ear \\
\hline Orifice & Eye & Tongue & Mouth & Nose & Skin \& Hair \\
\hline Tissues & Tendons & Vessels & Muscles & Grief & White \\
\hline Emotions & Anger & Joy & Pensiveness & Plack \\
\hline Colour & Blue $/$ Green & Red & Sweet & Pungent & Salty \\
\hline Taste & Sour & Bitter & Sing & Groan \\
\hline Voice & Shout & Laugh & &
\end{tabular}

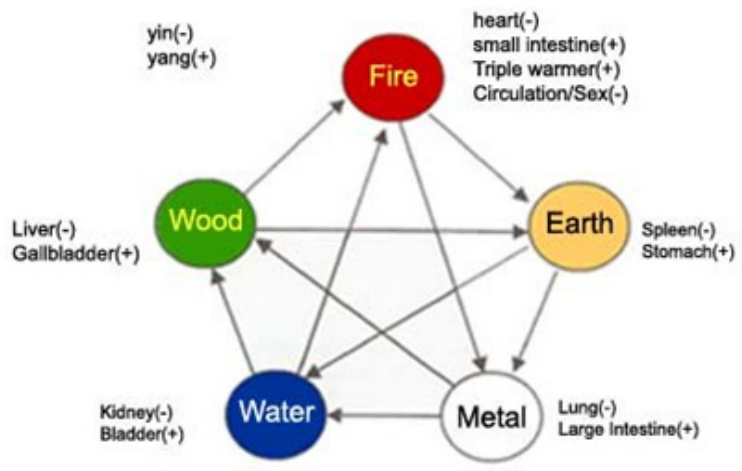

Figure 5: Five Elements theory and the Generation Cycle and Control Cycle.

In the Five Elements theory, we have the generation cycle where Fire generates energy for the Earth, which passes energy to the Metal, which gives energy to the Water, which generates energy for the Wood, which passes energy to the Fire, as shown in the (Figure 5) [17]. We also have the control cycle where the Fire controls the Metal that controls the Wood that controls the Earth that controls the Water that controls the Fire, also shown in the (Figure 5) [17]. The physiopathology of myocardial infarction in the energy level is believed to involve the production of internal Dampness and Phlegm that leads to internal obstruction including Qi stagnation and Blood stagnation. The formation of Dampness and Phlegm comes from the imbalance of the Spleen meridian, a massive organ of the Five Elements theory (Figure 6) [9]. The author, in an attempt to demonstrate the quantity of energy in each massive organ, she used a procedure called radienthesia to measure the energy of each massive organ. In some articles foung in the literature, such as the Geometry of Emotions, Using Chakra Acupuncture and 5-Phase Theory to Describe Personality Archetypes for Ckinical Use, written by Christopher R Chase, he is demonstrating on his article, the association between the Five Elemets and the chakras' energies centers [18].

Using his reasoning, the author measured the chakras' energies centers and with this process, she could know how was the energy inside each massive organ according to the Five Elemets theory, in traditional Chinese medicine. She began to use this method, because in China, they usually measures the energy in each massive organ using pulse, but as this method cannot be demonstrated cientfically, she began to use the radiesthesia procedure, and using this method , she can measure the energy and show to the patient how was the energy in each chakra, differently when she only uses the measure thought the pulse method [19].As there are seven chakras' and five elements, the correspondence between them is done as follows: first and seventh chakras' are related to Wood and Liver, second and sixth chakras' are related to Water and Kidney, third chakra corresponds to Fire and Heart, fourth chakra is Metal and Lung and the fifth chakra corresponds to Earth and Spleen (Figure 6) [1718]. In this article, the radiesthesia was used to measure the level 
of the chakras' energies centers of the analyzed patient. In other words, the author was measuring the energy of each organ in the Five Elements theory. Each element is responsible to send energy to the next element, as you can see in the generation cycle., shown in the (Figure 5) [17-18].

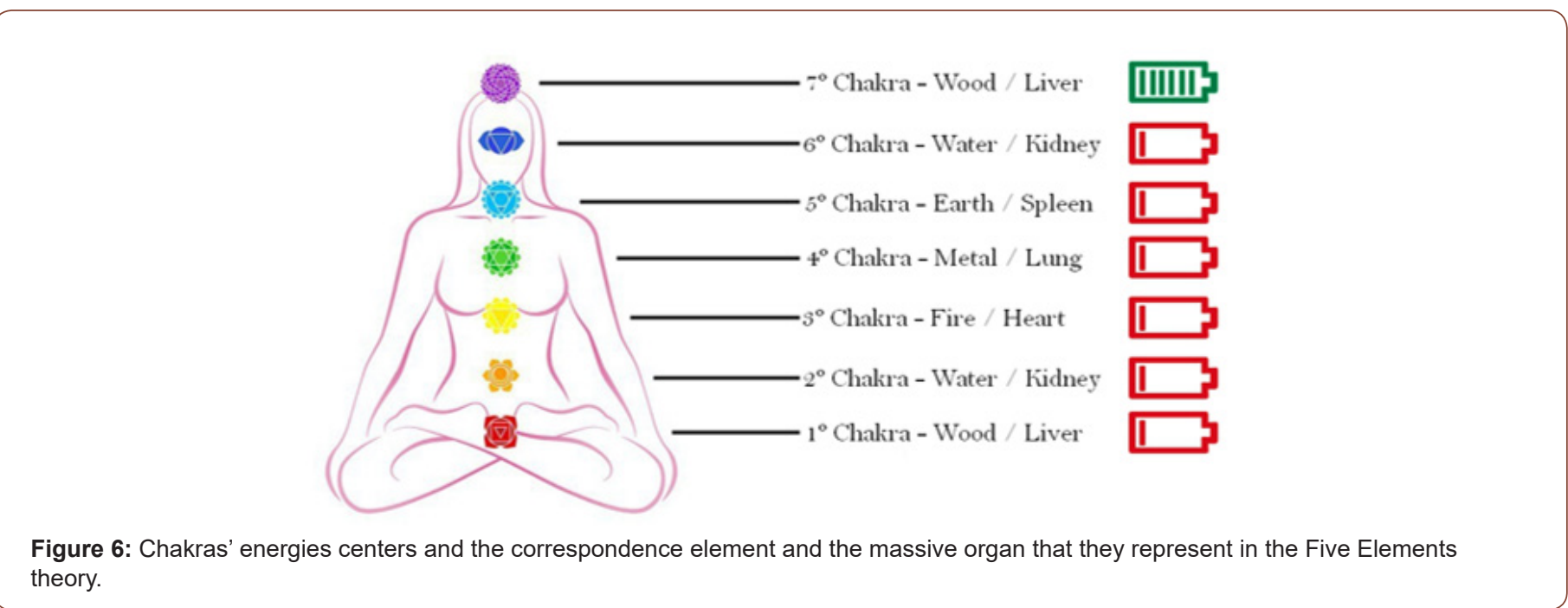

The procedure of radiesthesia is done using a crystal pendulum (Figure 7). This pendulum is placed in front of each person's chakra. The pendulum may stay still, or move clockwise or counterclockwise. These movements are classified in a scale from 1 to 8 , 1 being the minimum level of energy and 8 the normal level. If the pendulum does not move, the patient has no energy on the evaluated chakra. If it moves clockwise, it will be classified from 1 to 8 according to the intensity of the movement. When the movement is counter-clockwise may be external interference, and it has to be studied individually [20]. The Yin and Yang energies are produced in the second chakra on the Kidney. The fifth chakra absorbs nutrients and is where the Blood is formed (Figure 8) [17]. The Blood is stored in the first chakra, which is the Liver and is commanded by the third chakra which is the Heart [17]. The distribution of energy occurs in the first chakra, which is the Liver, and the fourth chakra which is the Lung [17]. In this case report presented in this article, all the chakras' of the patient were compromised, because according to the results made by the radiesthesia procedure, there is no adequate energy to allow Blood to circulate adequately inside the vessels, so the Blood circulation inside the vessels could be compromised, causing stagnation in the artery of the Heart, leading to three heart attacks in a short period. In the article entitled The Importance of Correcting Energy Imbalances in the Prevention and Treatment of Myocardial Infarction, published by Acta Scientific Medical Sciences, on May 2020, written by the author, she is affirming the necessity of treating the lack of energy in the chakras' energies centers in all the patients with history of myocardial infaction due to the fact that, according to her studies, patients with history of myocardial infarction, also have chakras' energies centers compromised, and they usually are in the lowest level of energy, and the necessity of treating these lack of energy to prevent another episode of myocardial infarction in patients with previous history of myocardial infarction or in patients with no history of myocardial infarction (Table 3) [9].

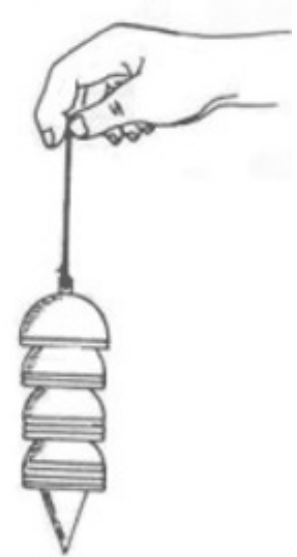

Figure 7: Crystal pendulum used in the measurement of the energy of the Five massive organs. 


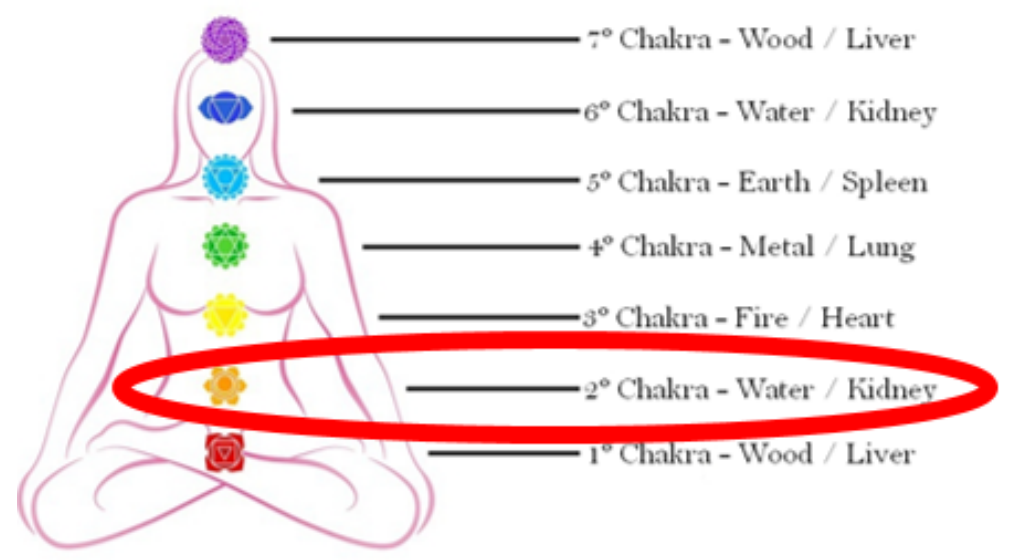

Figure 8: Chakras' energies centers and their functions.

Table 3: Homeopathy and crystal based medications used in the replacement of the chakras' energy centers.

\begin{tabular}{|l|c|c|c|}
\hline Chakras & Five Elements & Homeopathy Medications & Crystal-based medications \\
\hline $1^{0}$ Chakra & Wood/ Liver & Phosphorus & Garnet \\
\hline $2^{0}$ Chakra & Water/ Kidney & Natrium muriaticum & Orange calcite \\
\hline $3^{0}$ Chakra & Fire/ Heart & Sulphur & Rhodochrosite \\
\hline $4^{0}$ Chakra & Metal/ Lung & Silicea & Bmerald \\
\hline $5^{0}$ Chakra & Earth/ Spleen & Calcarea carbonica & Quartz \\
\hline $6^{0}$ Chakra & Water $/$ Kidney & Tone $2^{0}$ chakra & Tiger eye \\
\hline $7^{0}$ Chakra & Wood/ Liver & Tone $1^{0}$ chakra & \\
\hline
\end{tabular}

When the internal massive organs are without energy, acupuncture and diet are not enough to replenish the lack of energy, so the necessity of using medicines like Chinese herbs to replenish the energy of these organs. However, in Brazil, these herbs are difficult to find, so the author began to study homeopathy and during her course in Brazil, she created a new theory in homeopathy using homeopathic medications but according to traditional Chinese medicine reasoning. In this case, she developed a theory using homeopathy combining the knowledge of Chinese medicine, so Western doctors can use this reasoning easily to use and accessible to everyone. These medications are described in the article Constitutional of Homeopathy of the Five Elements based on Traditional Chinese Medicine published on July 2020 by Acta Scientific Medical Sciences [17].
The reason the author prefers to use highly diluted medications is based on the Arndt-Schulz Law. According to this law, for all substances, small doses stimulate, moderate doses inhibit and overdoses kill. According to this law, highly diluted drugs improve organic processes, while high-concentrated medicines harm health [21]. (Figure 9), it is possible to see that the lower part of the zero corresponds to the inhibitory effect of the drug while the part above the zero has the stimulating effect. We can observe that the more concentrated the drug, the more deleterious effect it will cause in the body. On the contrary, the more diluted the drug, the more stimulating effect on the patient's energy will occur [21]. For this reason, in patients with history of myocardial infarction, it is better to reduce the use of highly concentrated medications and chose the medications that is highly diluted to harm less the vital energy of this patients that is already low [9].

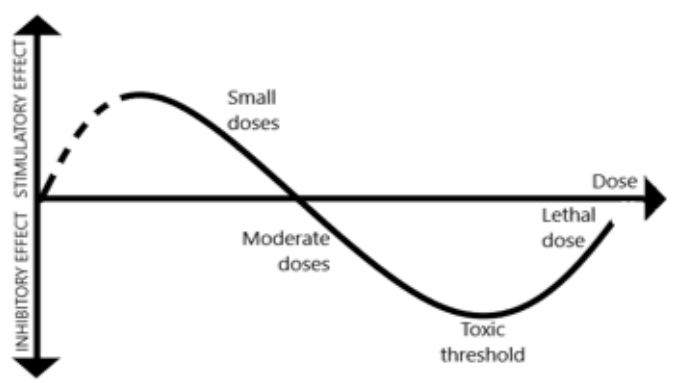

Figure 9: Arndt-Schulz Law. 
The lack of energy that this patient presented is not an isolated case, as shown by a study the author did in her clinic in Brazil, and presented in several webinars in 2020, such as in infectious disease webinar conference, that was held in august 2020. In this presentation, the author selected 409 files of patients who measured the energy of the chakras' and she revealed that $90 \%$ of her patients have no energy in all the chakras' energies centers, from one to six, meaning that all the internal massive organs were without energy. This means that the equilibrium between the energies Yin, Yang, Qi and Blood are also compromised leading to propensity to a variety of diseases such as diabetes, hypertension, myocardial infarction, cancers, etc [7-14]. This lack of energy could be linked to the increase the chances of such as myocardial infarction without arterial obstruction in young adults, as the prevalence of myocardial infarction is above 45 years old in a study made by Rajeev Bhadwa, in an article entitled Myocardial infarction in young adults-risk factors and pattern of coronary artery involvement [22]. Another point that should be emphasized when we observe that the majority of infarctions without arterial obstruction occur in women is that they present a loss of blood every month, thus losing more energy when compared to men, in addition to not often having an adequate diet, not providing this replenishment of energy (Table 4) [23].

Table 4: Chakras' energies centers result in a research made from 2015 to 2020.

\begin{tabular}{|c|c|c|c|}
\hline \multicolumn{4}{|c|}{ Chakras energy and main diagnoses } \\
\hline Ages & \multirow{2}{*}{$0-19$} & \multirow{2}{*}{$20-59$} & \multirow{2}{*}{$60-90$} \\
\hline Chakras & & & \\
\hline 7 & 8 & 8 & 8 \\
\hline 6 & 1 & 1 & 1 \\
\hline 5 & 1 & 1 & 1 \\
\hline 4 & 1 & 1 & 1 \\
\hline 3 & 1 & 1 & 1 \\
\hline 2 & 1 & 1 & 1 \\
\hline 1 & 1 & 1 & 1 \\
\hline $\mathrm{AE}$ & 1 & 1 & 1 \\
\hline Total of Patients & 26 & 170 & 86 \\
\hline Main Western diagnoses & Anxiety Depression & Anxiety Headache & Anxiety knee pain \\
\hline Total diagnoses & 11 & 105 & 37 \\
\hline Percentage & $42,31 \%$ & $61,76 \%$ & $43,02 \%$ \\
\hline \multirow{3}{*}{ Main Oriental diagnoses } & Yin / Yang & Yin & Yin \\
\hline & Yin /Blood & Yin / Yang & Yin / Internal Heat \\
\hline & & & Yin / Yang / Internal Heat \\
\hline Total diagnoses & 4 & 38 & 28 \\
\hline Percentage & $15,38 \%$ & $22,35 \%$ & $32,56 \%$ \\
\hline
\end{tabular}

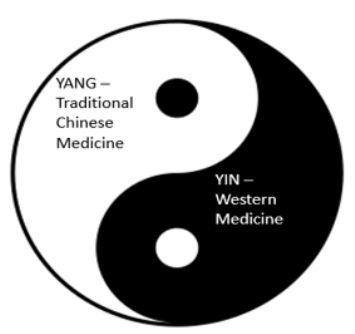

Figure 10: Metaphor of Yin and Yang of Western medicine and traditional Chinese medicine.

In order to treat patients with myocardial infarction without arterial obstruction, it is important to comprehend the importance of the different medical perspectives. The body is not only physical and constituted by organs and tissues. It is also formed by energy. In the figure 10, a metaphor of Yin and Yang as the different kinds of medicine was created by the author. Nowadays, Western medicine and traditional Chinese medicine are opposite, but they could be complementary [7-14]. Traditional Chinese medicine can be considered as Yang energy, and Western medicine is considered Yin energy, already materialized. In the same way of the relationship of the Yin and Yang, traditional Chinese medicine starts where Western medicine ends, and vice versa. The relationship is not static, but 
dynamic [7-14]. The author wants to emphasize in this article that all the tools used in the treatment of this patients were considered medical specialties since 1995 and 1980 for acupuncture and homeopathy, respectively, by the Brazilian Federal Medical Council [24].

\section{Conclusion}

The conclusion of this study is that, the possible factor that had induce the myocardial infarction without arterial obstruction in this patient was the complete lack of energy in all her chakras' energies centers, leading to stagnation of Blood in the coronary arteries. The correct treatment of this lack of energy will prevent future myocardial infarctions events and prevent the development of another disease.

\section{Acknowledgement}

None.

\section{Conflict of Interest}

No conflict of interest.

\section{References}

1. Pasupathy S, Rosanna Tavella, Simon McRae, John F Beltrame (2015) Myocardial Infarction With Non-obstructive Coronary Arteries Diagnosis and Management. Eur Cardiolv 10(2): 79-82.

2. Jacqueline E Tamis-Holland, Hani Jneid (2018) Myocardial Infarction With Nonobstructive Coronary Arteries (MINOCA): It's Time to Face Reality. J Am Heart Assoc 7(13): e009635.

3. Yapijakis C (2009) Hippocrates of Kos, the father of clinical medicine, and Asclepiades of Bithynia, the father of molecular medicine. Review. In Vivo 23(4): 507-514.

4. Huang WL (2020) The Importance of Correcting Energy Imbalances in the Prevention and Treatment of Myocardial Infarction. Acta Scientific Medical Sciences 4(6): 20-27.

5. Giampaolo Niccoli, Giancarla Scalone, Filippo Crea (2015) Acute myocardial infarction with no obstructive coronary atherosclerosis: mechanisms and management. Eur Heart J 36(8): 475-481.

6. Huang WL (2019) The Importance of Correcting Energy Imbalances and Chakras' Energy Deficiencies in the Treatment of Patients with Glaucoma. Clin Res Ophthalmol 2(2): 1-9.

7. Huang WL (2019) Why Are Diabetic Patients Still Having Hyperglycemia Despite Diet Regulation, Antiglycemic Medication and Insulin. Int J Diabetes Metab Disord 4(2): 1-14
8. Huang WL (2020) Energy Imbalances and Chakras Energy Replenishment to Treat Patients with Urinary Incontinence and Sexual Dysfunction Post-Cancer Prostatectomy. J Androl Gynaecol 8(1): 7.

9. Huang WL (2020) The Importance of Correcting Energy Imbalances in the Prevention and Treatment of Myocardial Infarction. Acta Scientific Medical Sciences 4(6): 20-27.

10. Huang WL (2019) Energy Alterations as the UnderlYing Cause of Primary Hypertension. ARC J Nephrol 4(2): 33-44.

11. Huang WL (2019) The Importance of Treating Energy Imbalances and Chakras' Energy Deficiencies in Patients with Chronic Urticaria Reactions Allergy drugs. Clin Immunol 3: 118.

12. Huang WL (2018) Why Do Patients Still Catch Hospital Infections Despite the Practice of Infection Prevention and Control Programs? Acta Scientific Microbiol 1(4): 34-43.

13. Huang, WL (2019) Why Do Patients Still Have Anxiety Symptoms Despite the Use of Psychotropic Medications? Archives of Neurology and Neuro Disorders 2(2): 13-23.

14. Huang WL (2020) Chakra's Energy Deficiency as the Main Cause of Infertility in Women. Obstet Gynecol Int J 11(2): 83-91.

15. Jung C (1967) The I Ching or Book of Changes. Princeton University. Outubro.

16. Bing 0, Zhen G (1996) Essentials of Traditional Chinese Medicine (Series of Traditional Medicine for Foreign Readers). Shandong Science and Technology Press.

17. Huang WL (2020) Constitutional Homeopathy of Five Elements Based on Traditional Chinese Medicine. Acta Scientific Medical Sciences 4(7): $57-69$

18. Chase C (2018) The Geometry of Emotions: Using Chakra Acupuncture and 5-Phase Theory to Describe Personality Archetypes for Clinical Use. Med Acupunct 30(4): 167-178.

19. Traditional Chinese Medicine Pulse Diagnosis on a Smartphone Using Skin Impedance at Acupoints: A Feasibility Study.

20. (2020) What is Radiesthesia and How Does It Work? Centre-Region.eu.

21. LEESER O (1953) Support of homeopathy by the Arndt-Schulz law. Hippokrates 24(14): 417-421.

22. Bhardwaj R, Arvind Kandoria, Rajesh Sharma (2014) Myocardial infarction in young adults-risk factors and pattern of coronary artery involvement. Niger Med J 55(1): 44-47.

23. Tamis-Holland JE, Jneid H (2018) Myocardial infarction with nonobstructive coronary arteries (MINOCA): It's time to face reality. J Am Heart Assoc 7(13): e009635.

24. Cremepe (2006) Homeopatia e acupuntura reconhecidas e procuradas. 